sight, I approached slowly and stopped opposite them. Meanwhile, a bird flew out of the grounds, ran across the pasture, through the ditch and up onto the road to the car. $\mathrm{He}$ started pecking the hubcap. Some of the flock continued dancing, others froze in the erect alarm posture. I took a count and made notes, the pecking continued, then left for another site, returning in 20 minutes. A bird, presumably the same one, again came running toward the car. Both times he charged in the dancing threat: neck extended, head down, body horizontal, tail erect and wings decurved. This is the same posture adopted by a male confronting another at their mutual territory boundary. Evidently the car was being challenged.

Collectively, these random observations show the considerable tolerance Sharp-tailed Grouse on their dancing grounds have for a variety of short-term disturbances, including apparently severe ones resulting from cultivation. They demonstrate how strong the attachment is for the lek site and indicate the set pattern the birds follow when reacting to disturbances.

\title{
DO CROWS (C)AW IN CREE?
}

ANNA L. LEIGHTON, 328 Saskatchewan Crescent West, Saskatoon, Saskatchewan. S7N OA4

In his article "Crows and their (c)awing" (Blue Jay 49:123-125), Victor Friesen cites a fascinating array of sources on the question of whether crows say caw or aw. There is an additional source that has a bearing on this question. It is a source very relevant to Saskatchewan crows and older than any other source cited by Friesen the Saskatchewan Cree.

Many bird names in the Cree language are onomatopoeic, that is, they imitate the sound that the bird makes. (An example in English is the name "Chick-a-dee.") This is true for the Cree name for crow which is Ha-ha-siw or Aha-siw. The "siw" ending of this word indicates "bird," and the name means roughly "the bird that says ha-ha or aha." This places the Cree clearly in the aw camp for crows, but interestingly enough, the Cree name for the raven, also onomatopoeic, is Ka-ka-giw. (I am not sure what the "giw" ending here signifies.)

Some other onomatopoeic bird names in Cree are piskwa and kas- kas-kus-kee-ka-chas. I will not tell you what these are as it might be fun to try to guess them by the sound. The second one should not be too difficult for people who know the bird's song. Hint: the fourth syllable is raised in pitch and drawn out longer than the others and the fifth and sixth syllables fall rapidly from the fourth.

Some Cree bird names are descriptive of the bird's appearance or behaviour rather than the sound it makes. Two examples are, in English translation, "little raven" and "raven duck." Can you guess what birds these refer to? [See page 128 for the answers to these questions.]

This information is from my own experience with Cree speakers in northern Saskatchewan. Bird names, a lively part of the Cree language still spoken extensively in parts of the province, have not been collected in any one place that I know of, although some bird names do occur as entries in the various dictionaries of the Cree language. 